\title{
Prediction of congenital hypothyroidism based on initial screening thyroid- stimulating-hormone
}

David S. Saleh ${ }^{1,3^{*}}$, Sarah Lawrence ${ }^{1}$, Michael T. Geraghty ${ }^{2}$, Patricia H. Gallego ${ }^{4}$, Karen McAssey ${ }^{5}$, Diane K. Wherrett ${ }^{6}$ and Pranesh Chakraborty ${ }^{2,7^{*}}$

\begin{abstract}
Background: In thyroid-stimulating-hormone (TSH)-based newborn congenital hypothyroidism (CH) screening programs, the optimal screening-TSH cutoff level is critical to ensuring that true cases of $\mathrm{CH}$ are not missed. Screening-TSH results can also be used to predict the likelihood of $\mathrm{CH}$ and guide appropriate clinical management. The purpose of this study is to evaluate the predictive value of various screening-TSH levels in predicting a diagnosis of $\mathrm{CH}$ in the Ontario Newborn Screening Program (ONSP).

Methods: The initial screening and follow-up data of 444,744 full term infants born in Ontario, Canada from April 1, 2006 to March 31, 2010 were analyzed. Confirmed CH cases were based on local endocrinologists' report and initiation of thyroxine treatment.

Results: There were a total of 541 positive screening tests ( 1/822 live births) of which 296 were true positives ( 1:1,500 live births). Subjects were further subdivided based on screening-TSH and positive predictive values (PPV) were calculated. Twenty four percent in the 17-19.9 mIU/L range were true positives. In the 17-30 $\mathrm{mIU} / \mathrm{L}$ range, $29 \%$ were true positives with a significantly higher PPV for those sampled after (43\%) rather than before $(25 \%) 28 \mathrm{~h}$ of age $(p<0.02)$. Seventy three percent of neonates with an initial screening-TSH of $\geq 30 \mathrm{mIU} / \mathrm{L}$ and $97 \%$ of those with $\geq 40 \mathrm{mIU} / \mathrm{L}$ were later confirmed to have $\mathrm{CH}$.

Conclusions: Infants with modestly elevated screening positive TSH levels between 17 and $19.9 \mathrm{mIU} / \mathrm{L}$ have a significant risk (24\%) of having $\mathrm{CH}$. The very high frequency of true positives in term newborns with initial TSH values $\geq 30 \mathrm{mIU} / \mathrm{L}$ suggests that this group should be referred directly to a pediatric endocrinologist in an effort to expedite further assessment and treatment. Screen positives with a modestly elevated TSH values (17-19.9 $\mathrm{mIU} / \mathrm{L}$ ) need to be examined in more detail with extended follow-up data to determine if they have transient or permanent $\mathrm{CH}$.
\end{abstract}

Keywords: Congenital hypothyroidism, Thyroid stimulating hormone, Thyroid hormone, Newborn screening

\section{Background}

Thyroid hormone is essential for normal central nervous system development - especially in the first 3 years of life [1]. For children with untreated $\mathrm{CH}$, the result is permanent, irreversible cognitive delay, impaired motor function and growth. This can be prevented by early

\footnotetext{
* Correspondence: salehd@hdh.kari.net; pchakraborty@cheo.on.ca 'Division of Pediatric Endocrinology and Metabolism, Department of Pediatrics, University of Ottawa, Ottawa, ON, Canada

2Department of Pediatrics, University of Ottawa, Ottawa, ON, Canada Full list of author information is available at the end of the article
}

detection and treatment $[2,3]$. As a result, screening programs to detect $\mathrm{CH}$ in the neonatal period were developed in the early 1970's and adopted by many countries throughout the world. In Ontario, Canada, a primary TSH with no second-tier test strategy has been used by Newborn Screening Ontario (NSO) since April 2006.

Since the introduction of screening programs, screeningTSH cutoffs and the predictive value of various screeningTSH levels has been the subject of debate [4-6], and a variety of strategies are used. Some programs choose a 
standard TSH screen cutoff, often in the $20-30 \mathrm{mIU} / \mathrm{L}$ range, and consider all newborns below the cutoff as negative for $\mathrm{CH}$. Others choose 2 cutoffs: a standard cutoff, and a second lower threshold, as low as $6 \mathrm{mIU} / \mathrm{L}$. This second group is considered "low-risk" for $\mathrm{CH}$, and goes on to have follow up thyroid function testing $[4,7]$. In such programs screening samples are typically collected at a later age, which also explains the lower threshold in that we know that TSH levels decline with time after birth. Regardless of the strategy employed, there has long been established a correlation between the initial screening-TSH level and the risk of $\mathrm{CH}$ [8]. The primary purpose of this study is to formally evaluate the predictive value of the initial screeningTSH result in Ontario.

\section{Methods}

Subjects were identified from all newborns screened in Ontario, Canada between April 1, 2006 and March 31, 2010. Confirmatory thyroid function testing bloodwork, thyroid scan data and patient management information was collected by the individual centre and submitted to the ONSP. We collected all data directly from the ONSP representing the 5 major pediatric centers in Ontario. Aggregate NSO information is made publically available in an annual report posted on the NSO website (www.newbornscreening.on.ca). The record level data used for this analysis is not publically available. Inquiries about access to NSO data should be directed to Dr. Pranesh Chakraborty (Executive Director, NSO).

Stop date was chosen as a new data collection system was implemented beyond this date. Inclusion criteria included term newborns ( $\geq 37$ weeks gestational age) whose screening blood sample was collected later than $24 \mathrm{~h}$ of age. All newborns screened $<24 \mathrm{~h}$ are routinely re-screened with a bloodspot sample as part of NSO protocol. Subjects of mothers who were reported to be on anti-thyroid medication were excluded. Multiple birth newborns were not excluded. Screening blood samples were collected by heel stick bloodspot on filter paper, and analyzed using an automated Perkin-Elmer autoDELFIA immunoassay measuring TSH in mIU/L blood volume. No changes to the assay occurred during the study period. Newborns with an initial screeningTSH $\geq 17 \mathrm{mIU} / \mathrm{L}$ had confirmatory duplicate TSH bloodspot testing on the same sample and were referred to a local physician for further evaluation and management if the average of three TSH results was $\geq 17 \mathrm{mIU} / \mathrm{L}$. Data collected consisted of the short term follow up information routinely collected by NSO, including screening and confirmatory TSH values, time of screening sample collection, gestational age, birth-weight and final diagnosis (based on local physician's report). Subjects were defined as having true $\mathrm{CH}$ if they were started on thyroxine replacement therapy at the discretion of their local endocrinologist - a decision based primarily on confirmatory plasma TSH and fT4 testing, and thyroid imaging (thyroid scan or ultrasound).

The Fisher Exact Test was used to compare positive predictive values between age-of-sample collection groups $<28$ and $\geq 28 \mathrm{~h}$ (median age of sample collection was $28 \mathrm{~h}$ ).

Patients in the study were anonymized and assigned a unique study identifier number. This study was approved by the CHEO Research Ethics Board.

\section{Results}

Subjects included 444,744 term newborns born between April 1, 2006 and March 31, 2010, of whom 541 newborns screened positive representing a screen positive rate of approximately 1 in 822 newborns. Follow-up data was available for all screen positive subjects, and 296 were later confirmed to have $\mathrm{CH}$ representing an incidence of approximately 1:1,500 term newborns.

Table 1 shows the positive predictive value and sensitivity for various TSH screen cutoff levels. At a screening-TSH cutoff of $17 \mathrm{mIU} / \mathrm{L}, 296$ of 541 newborns were diagnosed with $\mathrm{CH}$ and started on treatment yielding a positive predictive value of $54.7 \%$. For the purposes of this analysis, we made the assumption that none of the 444,193 newborns who screened negative actually had $\mathrm{CH}$, yielding a sensitivity for the program of close to $100 \%$. When the TSH screening cutoff is increased to $20 \mathrm{mIU} / \mathrm{L}$, although the positive predictive value increases to $72.9 \%$, the sensitivity decreases significantly to $83.8 \%$.

Follow-up data from the 541 screen-positive infants was then analyzed based on various screening-TSH ranges (Table 2). Of the 201 newborns with screeningTSH results between 17-19.9 mIU/L, 48 were later confirmed to have $\mathrm{CH}$, yielding a positive predictive value (PPV) of $23.9 \%$ for those who screen positive in this range. The PPV increases to $39 \%$ for screening-TSH results of $20-29.9 \mathrm{mIU} / \mathrm{L}, 76.5 \%$ for a screening-TSH of $30-39.9 \mathrm{mIU} / \mathrm{L}$, and $97.2 \%$ for a screening-TSH $\geq$ $40.0 \mathrm{mIU} / \mathrm{L}$.

Newborns with 'grey zone' screening TSH of 17-29.9 $\mathrm{mIU} / \mathrm{L}$, the PPV was $30 \%$ (98 of 330). Of confirmed positive cases with screening TSH 17-29.9 mIU/L, $47 \%$ (20 of 43) had a low free T4 on confirmatory thyroid function testing (according to local lab normal ranges), compared with $66 \%$ (63 of 96) of those whose screening TSH was $\geq 30$. Free T4 data was only available for $47 \%$ of cases. Of those subjects whose screening-TSH level was $17-29.9 \mathrm{mIU} / \mathrm{L}, 27 \%$ (12 of 45 ) had evidence of thyroid dysgenesis on thyroid scan, versus $68 \%$ (82 of 120 ) in the screening-TSH $\geq 30 \mathrm{mIU} / \mathrm{L}$ range (Table 3 ). Thyroid scan data was only available for $56 \%$ (165 of 294) of confirmed positives overall [46 \% (45 of 98) in 
Table 1 Positive predictive values and sensitivities for the $\mathrm{CH}$ ONSP at various screening-TSH cutoff values

\begin{tabular}{llll}
\hline $\begin{array}{l}\text { TSH Screen } \\
\text { Cutoff (m/U/L) }\end{array}$ & $\begin{array}{l}\text { True Positives/ } \\
\text { Screen Positives }\end{array}$ & $\begin{array}{l}\text { Positive Predictive } \\
\text { Value }(\%)\end{array}$ & $\begin{array}{l}\text { Sensitivity } \\
(\%)\end{array}$ \\
\hline$\geq 17$ & $296 / 541$ & $55 \%$ & $\sim 100 \%$ \\
$\geq 20$ & $248 / 340$ & $73 \%$ & $84 \%$ \\
$\geq 30$ & $198 / 211$ & $94 \%$ & $67 \%$ \\
$\geq 40$ & $172 / 177$ & $97 \%$ & $58 \%$ \\
$\geq 50$ & $157 / 159$ & $99 \%$ & $53 \%$ \\
\hline
\end{tabular}

the $17-29.9 \mathrm{mIU} / \mathrm{L}$ range, and $61 \%$ (120 of 196) in the screening-TSH $\geq 30 \mathrm{mIU} / \mathrm{L}$ range]. Although confirmatory serum TSH levels were likely drawn for all screen positive patients as per standard clinical practice, we received data only 169/296 (57 \%) of subjects. In 138 of 296 cases, we received confirmatory TSH, fT4 and thyroid scan data.

The PPV of newborns with screening-TSH levels between 17-30 mIU/L and whose blood sample was collected at $>28 \mathrm{~h}$ of age was significantly higher than those whose samples were collected 24-28 h of age (43\% vs. $25 \% ; p=0.002$; Fig. 1).

\section{Discussion}

This cohort of 444,744 newborns yielding 541 screen positive subjects represents one of the largest recently published analyses of a $\mathrm{CH}$ screening program. The incidence of $\mathrm{CH}$ of 1:1,500 is comparable to reports in other jurisdictions, although higher than most industrialized, iodine replete countries and suggests efficient ascertainment of mild cases of $\mathrm{CH}$ [9]. Diagnosed newborns include those with both permanent and transient forms of $\mathrm{CH}$. This could lead to over-diagnosis of $\mathrm{CH}$ as many clinicians will treat confirmed screen positive patients until 3 years of age, then reassess to determine if they have a transient form of $\mathrm{CH}$ [10]. Elevated screening and diagnostic TSH values can also be secondary to severe illness [11], maternal TSH receptor blocking antibodies [12], maternal iodine deficiency [13, 14] and excess [15], infant exposure to iodine [16], errors in the screening procedure, and newborns conceived by in vitro fertilization [17] or delivered by caesarian section [18].

Table 2 Positive predictive values for the CH ONSP at various screening-TSH ranges

\begin{tabular}{lllll}
\hline $\begin{array}{l}\text { TSH Screen Range } \\
(\mathrm{mIU} / \mathrm{L})\end{array}$ & $\begin{array}{l}\text { Screen } \\
\text { Positives }\end{array}$ & $\begin{array}{l}\text { True } \\
\text { Positives }\end{array}$ & $\begin{array}{l}\text { False } \\
\text { Positives }\end{array}$ & $\begin{array}{l}\text { Positive } \\
\text { Predictive Value }\end{array}$ \\
\hline $17-19.9$ & 201 & 48 & 153 & $24 \%$ \\
$20-29.9$ & 129 & 50 & 79 & $39 \%$ \\
$30-39.9$ & 34 & 26 & 8 & $76 \%$ \\
$\geq 40$ & 177 & 172 & 5 & $97 \%$ \\
\hline
\end{tabular}

Table 3 Thyroid scan results for confirmed $\mathrm{CH}$ cases

\begin{tabular}{llll}
\hline $\begin{array}{l}\text { Thyroid } \\
\text { Scan result }\end{array}$ & $\begin{array}{l}\text { TSH 17-30 group } \\
\text { (frequency [\%]) }\end{array}$ & $\begin{array}{l}\text { TSH }>30 \text { group } \\
\text { (frequency [\%]) }\end{array}$ & $\begin{array}{l}\text { All Confirmed } \\
\text { Positive cases }\end{array}$ \\
\hline $\begin{array}{l}\text { Normal } \\
\text { Scan }\end{array}$ & $28[62]$ & $33[28]$ & $61[37]$ \\
$\begin{array}{l}\text { Ectopic } \\
\text { gland }\end{array}$ & $8[18]$ & $53[44]$ & $61[37]$ \\
Athyrosis & $1[2]$ & $29[24]$ & $30[18]$ \\
$\begin{array}{l}\text { Other } \\
\text { Dysplasia }\end{array}$ & $3[7]$ & $0[0]$ & $2[1]$ \\
$\begin{array}{l}\text { All } \\
\text { Dysplasia }\end{array}$ & $12[27]$ & $82[68]$ & $94[57]$ \\
$\begin{array}{l}\text { Decreased } \\
\text { uptake }\end{array}$ & $5[11]$ & $5[4]$ & $10[6]$ \\
Total & 45 & 120 & 165 \\
\hline
\end{tabular}

There is a wide range of screening-TSH cutoffs used in neonatal screening programs including a low of 6 $\mathrm{mIU} / \mathrm{L}$ in Wales [4], to a high of $30 \mathrm{mIU} / \mathrm{L}$ in Turkey [19]. Much of this discrepancy has to do with the age of sample collection (as TSH falls over the first few days of life), or specific assay used to measure TSH. Hence, our program's data based on a TSH cutoff of $17 \mathrm{mIU} / \mathrm{L}$ may not be generalizable to other programs that collect bloodspot samples at different ages, or use a different TSH immunoassay. Some programs use a TSH screen cutoff of $20 \mathrm{mIU} / \mathrm{L}$. Increasing the cutoff in Ontario from 17 to $20 \mathrm{mIU} / \mathrm{L}$ would result in an unacceptable decrease in sensitivity from $100 \%$ to $84 \%$, thereby missing $16 \%$ of currently identified cases. Of the 20 patients with a screening TSH level in the 17-20 range, at least

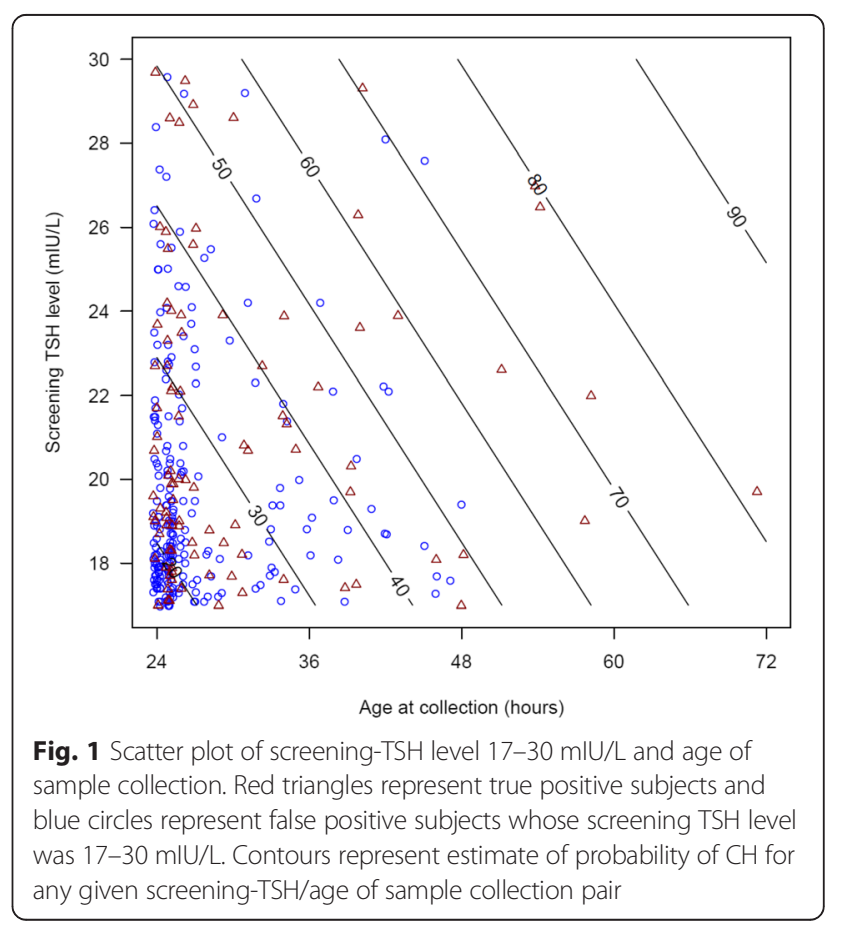


one had athyreosis indicated by thyroid scan (thyroglobulin level was not measured), and 9 had a low free T4 values on confirmatory thyroid function testing, suggesting classical $\mathrm{CH}$. This underscores the importance of maintaining a low screening cutoff level of at most 17 $\mathrm{mIU} / \mathrm{L}$ in order to detect an acceptable percentage of those with $\mathrm{CH}$.

The positive predictive value of newborns with mild to moderate elevations of screening-TSH values in the 1730 range is $30 \%$. This increases significantly to $76 \%$ with a screening-TSH of 30-39.9 mIU/L, and to $97 \%$ with a screening-TSH $\geq 40 \mathrm{mIU} / \mathrm{L}$. This is consistent with a published report demonstrating that $41 \%$ of newborns with TSH levels between $20-50 \mathrm{mIU} / \mathrm{L}$ had $\mathrm{CH}$ [8]. Given the high PPV of $94 \%$ for true $\mathrm{CH}$ with a screening TSH over $30 \mathrm{mIU} / \mathrm{L}$ and the serious, permanent developmental consequences of untreated $\mathrm{CH}$, we propose that all such newborns should be referred directly for specialist evaluation in an effort to expedite further assessment and treatment.

Time of sample collection is important to consider in conjunction with absolute screening-TSH value in predicting the likelihood of $\mathrm{CH}$. When examining subjects with mild to moderately elevated screening-TSH levels of $17-30 \mathrm{mIU} / \mathrm{L}$, the PPV in newborns whose sample was collected $\geq 28 \mathrm{~h}$ of age was statistically higher than those whose samples were collected at $24-28 \mathrm{~h}$ of age (43\% vs. $25 \%, p=0.002$ ). TSH-based screening programs could potentially use age of sample collection data, in addition to absolute screening TSH level, as a better tool for capturing true positive cases and predicting the risk of true $\mathrm{CH}$ (Fig. 1).

Limitations of this study include our assumption that no infants with a screening-TSH result $<17 \mathrm{mIU} / \mathrm{L}$ actually had $\mathrm{CH}$, an assertion that may not be accurate. There is no formal system in place that captures $\mathrm{CH}$ patients who screen negative; however there were no reports of false negative screening results in children with clinically identified $\mathrm{CH}$ during the study period. More recently, there was one screen-negative infant confirmed to have $\mathrm{CH}$ in the context of a strong family history of hypothyroidism. This patient had a mild form of $\mathrm{CH}$. We would anticipate that most false screen-negative patients would be brought to the attention of the program or participating pediatric endocrinologist, particularly those patients with permanent $\mathrm{CH}$ and significant developmental morbidity secondary to untreated $\mathrm{CH}$.

The diagnosis of $\mathrm{CH}$ was based on local endocrinologist report and initiation of thyroxine treatment. This raises the limitations related to individual variations in clinical practice as well as determination of transient versus permanent $\mathrm{CH}$. A Japanese study that found a positive correlation between the prevalence of $\mathrm{CH}$ and regions with a lower concentration of adult and pediatric endocrinologists [20]. In Ontario, although non-specialists physicians are occasionally involved in the management of $\mathrm{CH}$ patients, the decision to treat is typically made by - or in conjunction with - a pediatric endocrinologist in virtually all cases. This may have reduced but would not eliminate the likelihood of overdiagnosis and treatment of some screen positive children.

A proportion of subjects may have a transient or mild form of $\mathrm{CH}$, particularly those whose screening-TSH level was in the lower end of the range. This notion is supported by Kemper et al. who found that $38 \%$ of children labeled as having $\mathrm{CH}$ by NBS no longer received thyroxine by age 4 [21]. Treatment of such infants is becoming increasingly controversial [6], as the neurodevelopmental consequences of withholding treatment in such cases is unclear. Despite this, in our study, of those subjects whose screening-TSH level was 17-29.9 mIU/L, approximately 1 in 4 had evidence of thyroid dysgenesis on thyroid scan, and nearly half had a low free T4 on confirmatory thyroid function testing, suggesting the possibility of clinically significant $\mathrm{CH}$. Thyroid scan and free T4 data was not available for all subjects. In addition, all confirmatory TSH values reported to the ONSP in confirmed cases (representing $57 \%$ of cases) were elevated above the reference range of the local laboratory.

Further clinical and biochemical evaluation of confirmed cases 3 years post-diagnosis will be necessary to conclusively determine the true incidence of permanent $\mathrm{CH}$. Unfortunately, this study was not designed to collect such information. Even complete imaging data would be insufficient, as some forms permanent thyroid dyshormonogenesis have a normal thyroid imaging at diagnosis [22]. Although treatment of mild or transient cases of $\mathrm{CH}$ is controversial, in the absence of a clear way to distinguish transient and permanent $\mathrm{CH}$ in the newborn period, and of data to support conservative observation in those with transient $\mathrm{CH}$, treatment is indicated.

\section{Conclusions}

This study demonstrates that infants with modestly elevated screening-TSH values between 17-19.9 mIU/L have a significant risk (24\%) of having $\mathrm{CH}$. The high frequency of true positives in those with screening-TSH levels over $30 \mathrm{mIU} / \mathrm{L}$ suggests that this group should be directly referred for specialist evaluation. Samples collected after $28 \mathrm{~h}$ of age have a significantly higher likelihood of being true positives with modest screening TSH elevations in the 17-30 mIU/L range - a finding that has possible implications in improving sensitivity and accuracy of identifying $\mathrm{CH}$ cases. Those who screen positive with TSH values between $17-20 \mathrm{mIU} / \mathrm{L}$ require 
further analysis and long-term follow up to determine if they have transient versus permanent $\mathrm{CH}$.

\section{Abbreviations}

TSH: Thyroid stimulating hormone; $\mathrm{CH}$ : Congenital hypothyroidism; ONSP: Ontario newborn screening program; FT4: Free thyroxine; PPV: Positive predictive value; NSO: Newborn screening Ontario.

\section{Competing interests}

The authors declare that they have no competing interests.

\section{Authors' contributions}

DS contributed to the original design of the study, analyzed the data, drafted the initial manuscript, and approved final manuscript as submitted. SL conceptualized and contributed to the original design of the study, reviewed and revised the manuscript, and approved the final manuscript as submitted. PG, KM and DW were site supervisors at their respective institutions and provided patient data, and reviewed and revised the manuscript. MG contributed to the original study design and critically reviewed the manuscript. PC was involved in the original design of the study and data analysis, and approved the final manuscript as submitted. All authors approved the final manuscript as submitted and agree to be accountable for all aspects of the work.

\section{Acknowledgements}

Nick Barrowman completed all statistical analyses of the data in this study and aided in interpretation of the data.

There were no funding sources for this study.

\section{Author details}

'Division of Pediatric Endocrinology and Metabolism, Department of Pediatrics, University of Ottawa, Ottawa, ON, Canada. ${ }^{2}$ Department of Pediatrics, University of Ottawa, Ottawa, ON, Canada. ${ }^{3}$ Department of Pediatrics, Queen's University, Kingston, ON, Canada. ${ }^{4}$ Department of Pediatrics, University of Western Ontario, London, ON, Canada. ${ }^{5}$ Division of Pediatric Endocrinology, Department of Pediatrics, McMaster University, Hamilton, ON, Canada. 'Division of Endocrinology, Department of Pediatrics, Hospital for Sick Children, University of Toronto, Toronto, ON, Canada. ${ }^{7}$ Newborn Screening Ontario, Children's Hospital of Eastern Ontario, Ottawa, Canada.

Received: 22 October 2014 Accepted: 27 January 2016

Published online: 02 February 2016

\section{References}

1. Porterfield SP, Hendrich CE. The role of thyroid hormones in prenatal and neonatal neurological development - current perspectives. Endocr Rev. 1993;14:94-106.

2. Dubuis JM, Glorieux J, Richer F, Deal CL, Dussault JH, Van Vliet G. Outcome of severe congenital hypothyroidism: Closing the developmental gaps with early high dose levo-thyroxine treatment. J Clin Enodcrinol Metab. 1996;81:222-7.

3. Bongers-Schokking JJ, de Muinck Keizer-Schrama SM. Influence of timing and dose of thyroid hormone replacement on mental, psychomotor, and behavioral development in children with congenital hypothyroidism. J Pediatr. 2005;147:768-74

4. Pryce RA, Gregory JW, Warner JT, John R, Bradley D, Evans C. Is the current threshold level for screening for congenital hypothyroidism too high? An audit of the clinical evaluation, confirmatory diagnostic tests and treatment of infants with increased blood spot thyroid-stimulating hormone concentrations identified on newborn blood spot screening in Wales. Arch Dis Child. 2007;92:1048

5. Korada M, Pearce MS, Ward Platt MP, Avis E, Turner S, Wastell H, et al. Difficulties in selecting an appropriate neonatal TSH screening threshold. Arch Dis Child. 2010;95:169-73.

6. Krude $\mathrm{H}$, Blankenstein $\mathrm{O}$. Treating patients not numbers: the benefi and burden of lowering TSH newborn screening cut-offs. Arch Dis Child. 2011:96:121-2.

7. UK Newborn Screening Programme Centre: Newborn blood spot screening in the UK. Policies and Standards, 2005. https://www.gov.uk/topic/populationscreening-programmes/newborn-blood-spot. Accessed 1 Feb 2016.
8. Klett M. Epidemiology of congenital hypothyroidism. Exp Clin Endocrinol Diabetes. 1997:105:19-23.

9. Kempers MJ, Lanting Cl, van Heijst AFJ, Trotsenburg ASP, Wiedijk BM, de Vijlder JJM, et al. Neonatal screening for congenital hypothyroidism based on thyroxine, thyrotropin, and thyroxine-binding globulin measurement: potentials and pitfalls. J Clin Endocrinol Metab. 2006:91:3370-6.

10. Parks JS, Lin M, Grosse SD, Hinton CF, Drummond-Borg M, Borgfeld L, et al. The impact of transient hypothyroidism on the increasing rate of congenital hypothyroidism in the United States. Pediatrics. 2010;125:S54-63.

11. Simpson J, Williams FL, Delahunty C, van Toor H, Wu SY, Ogston SA, et al. Serum thyroid hormones in preterm infants and relationships to indices of severity of intercurrent illness. J Clin Endocrinol Metab. 2005;90:1271-9.

12. Brown RS, Bellisario RL, Botero D, Fournier $L$, Abrams CA, Cowger ML, et al. Incidence of transient congenital hypothyroidism due to maternal thyrotropin receptor-blocking antibodies in over one million babies. J Clin Endocrinol Metab. 1996:81:1147-51.

13. Burns R, Mayne PD, O'Herlihy C, Smith DF, Higgins M, Stains A, et al. Can neonatal TSH screening reflect trends in population iodine intake? Thyroid. 2008;18:883-8.

14. Ares S, Quero J, Morreale de Escobar G. Neonatal iodine deficiency: clinical aspects. J Pediatr Endocrinol Metab. 2005;18 suppl 1:1257-62.

15. Connelly KJ, Boston BA, Pearce EN, Sesser D, Snyder D, Braverman LE, et al. Congenital hypothyroidism caused by excess prenatal maternal iodine ingestion. J Pediatr. 2012;161:760-2.

16. Smith VC, Cvoren BM, Wolfsodorf Jl. Hypothyroidism in a breast-fed preterm infant resulting from maternal topical iodine exposure. J Pediatr. 2006;149:56-567.

17. Sakka S, Malamitsi-Puchner A, Loutradis D, Chrousos GP, Kanaka-Gantenbein C. Euthyroid hyperthyrotropinemia in children born after in vitro fertilization. J Clin Endocrinol Metab. 2009;94:1338-41.

18. McElduff A, McElduff $P$, Wiley $V$, Wilcken B. Neonatal thyrotropin as measured in a congenital hypothyroidism screening program: Influence of the mode of delivery. J Clin Endocrinol Metab. 2005:90:6361-1.

19. Buyukgebiz A. Newborn screening for congenital hypothyroidism. J Ped Endo Metab. 2006:19:1291-8.

20. Gu YH, Kato T, Harada S, Inomata H, Aoki K. Time trend and geographic distribution of treated patients with congenital hypothyroidism relative to the number of available endocrinologists in Japan. J Pediatr. 2010;157:153-7.

21. Kemper AR, Ouyang L, Grosse SD. Discontinuation of thyroid hormone treatment among children in the United States with congenital hypothyroidism: findings from health insurance claims data. BMC Pediatr. 2010;10:9.

22. Schoen EJ, Clapp W, To T, Fireman BH. The key role of newborn thyroid scintigraphy with isotopic iodide $\left({ }^{123} \mid\right)$ in defining and managing congenital hypothyroidism. Pediatrics. 2004;114:e683-8.

\section{Submit your next manuscript to BioMed Central} and we will help you at every step:

- We accept pre-submission inquiries

- Our selector tool helps you to find the most relevant journal

- We provide round the clock customer support

- Convenient online submission

- Thorough peer review

- Inclusion in PubMed and all major indexing services

- Maximum visibility for your research

Submit your manuscript at www.biomedcentral.com/submit 